DOI: 10.20472/IAC.2019.047.021

\author{
TOSHIRO SAKAI \\ CHUBU UNIVERSITY, Japan
}

\author{
KATSUNORI FUJII \\ AICHI INSTITUTE OF TECHNOLOGY, Japan \\ NOZOMI TANAKA \\ TOKAI GAKUEN UNIVERSITY, Japan \\ KOHSUKE KASUYA \\ AICHI INSTITUTE OF TECHNOLOGY, Japan
}

\title{
RECENT TRENDS IN PHYSICAL FITNESS AND MOTOR ABILITY OF PRESCHOOL CHILDREN -TRENDS IN JAPAN SINCE 2000-
}

\begin{abstract}
:
In recent years, there has been concern in Japan of declining physical strength in early childhood. Consideration of lifestyle in modern society may provide suggestions on the appropriate level of physical strength and motor ability for modern children. Therefore, it may be necessary to show the physique and motor ability suitable for the generational background. The purpose of this study was to clarify the trends since 2000 in body shape, physical strength, and motor ability in early childhood in Japan. The data used were physique and motor ability data from 1969 to 2009 for young boys and girls in kindergartens and nursery schools in Aichi Prefecture surveyed by the Children's Growth and Development Society. The study subjects were kindergarten and nursery school girls (age 3-5 years old) in Aichi Prefecture, Japan. Physique (height and weight), quantitative motor ability (20 m dash, standing long jump, tennis ball throw, side step, one-leg hop, jump rope, hanging from a horizontal bar, one-leg standing, and ball bouncing), and general motor ability (jump over and under) were compared in the 1999 and 2009 school years. The results revealed that, compared with ten years earlier, height was approximately $0.9 \mathrm{~cm}$ shorter in 4-year-old girls and weight was approximately $0.3 \mathrm{~kg}$ lighter in 3- and 4-year-old girls in 2009. In physical strength and motor ability, the time for jump over and under was shorter in 3-year-olds, the number of times a rope jumped was higher and the time hanging from a horizontal bar was longer, and the time for jump over and under was shorter in 4-year-olds. In 5-year-olds, only an increase in the number of times a rope jumped increased. The tennis ball throw and side steps were not significantly different from 10 years earlier in any of the ages. Although physique, strength, and exercise improved with growth, it was found that many items decreased or remained the same in all age groups compared to those 10 years ago.
\end{abstract}

\section{Keywords:}

Preschool Girls, Physique, Physical strength, Secular trend, Least square approximation

JEL Classification: 100, I10, I19 